\title{
Primary bone tumors and tumor-like lesions of the wrist: a single-center experience
}

\author{
(1) Ömer Sofulu \\ Marmara University, Faculty of Medicine, Department of Orthopaedic Surgery and Traumatology, İstanbul, Turkey
}

Cite this article as: Sofulu Ö. Primary bone tumors and tumor-like lesions of the wrist: a single-center experience. J Health Sci Med 2022; 5(1): 131-137.

\begin{abstract}
Aim: The incidence of primary bone tumors of the wrist is increasing. The aim of this study was to examine the characteristics, treatment protocols, complication rates, and functional outcomes of bone tumors of the wrist treated in a tertiary orthopedic oncology center.

Material and Method: We retrospectively analyzed 93 patients with bone tumors located in the wrist (63 distal radius, 23 distal ulna, 7 carpal bone) who were operated on between 2005 and 2020. Demographic information was recorded. Functional outcomes were evaluated with the Musculoskeletal Tumor Society System (MSTS) scoring system.

Results: There were 57 male and 36 female patients. The average follow-up period was 32 months (range 16-163). There were 82 benign and 11 malignant lesions. Distal radius was the most common site of involvement. The most common type of benign tumor in the distal radius and distal ulna was the giant cell tumor (GCT; 26 and 10 patients, respectively). Among the malignant tumors in the distal radius, 5 were Ewing sarcoma, and 2 were osteosarcoma. All patients with malignant lesions underwent wide surgical resection and free vascularized fibular graft (FVFG) reconstruction. Of the malignant tumors in the distal ulna, 3 were Ewing sarcoma, and 1 was osteosarcoma. These were treated with wide resection and FVFG reconstruction $(\mathrm{n}=3)$ and wide resection and fibular strut graft $(n=1)$. The rarest site for tumors in the wrist was the carpal bones. Carpal bone lesions included scaphoid $(n=5)$ and lunate $(n=2)$ tumors. In all of these patients, pathological examination indicated intraosseous ganglion cysts. The average MSTS score of all patients was 27 (range 24-30). Of the 36 patients with GCT, 4 (11\%) developed local recurrence. One patient with Ewing sarcoma developed local recurrence and underwent secondary amputation. Distant lung metastasis was observed in 5 of 8 patients with Ewing sarcoma.

Conclusion: Our study confirmed that bone tumors in the wrist are rare. Most benign tumors can be treated with curettage and cement augmentation. For malignant tumors, it is possible to restore function with FVFG.
\end{abstract}

Keywords: Wrist, primary bone tumor, benign, malignant, incidence

\section{INTRODUCTION}

The wrist joint consists of the distal radius, distal ulna, and eight carpal bones. In addition to this complex bone structure, the wrist is also comprised of tendons and muscles on the volar and dorsal sides. This remains a challenge for orthopedic oncologists. Bone tumors are rarely found in hand and wrist compared to the other parts of the body (1). Although there are large patients series concerning bone tumors in the elbow and shoulder joint, to the best of our knowledge, studies on wrist tumors are limited to single-center experiences.

Several surgical procedures have been reported for primary bone tumors of the distal radius and distal ulna (2-5). Surgical methods for the treatment of carpal bones have been presented as case reports with limited numbers of patients $(6,7)$. Benign tumors are often treated with curettage, grafting, cement augmentation, or marginal excision $(5,8)$. The literature demonstrates the success of wide surgical resection with biological reconstruction in the treatment of malignant bone tumors $(9,10)$. Wrist bone tumors are becoming increasingly common, and advanced imaging methods allow early diagnosis and treatment (9). Therefore, it is important to understand the clinical, oncological and functional outcomes of wrist tumors to improve patient survival and function.

The aim of this study was to evaluate the incidence of wrist tumors, surgical methods, associated complication rates, and functional outcomes among patients operated for wrist tumors in our clinic. 


\section{MATERIAL AND METHOD}

The study was carried out with the permission of Marmara University Faculty of Medicine Clinical Research Ethics Committee (Date: 03.01.2020, Decision No: 09.2019.1033). All procedures were carried out in accordance with the ethical rules and the principles of the Declaration of Helsinki.

We retrospectively reviewed the files of 105 patients who were surgically treated for wrist tumors between 2005 and 2020. We excluded eight patients with metastatic lesions and four patients due to irregular follow-up. Of the remaining 93 patients, 63 had distal radius tumors, 23 distal ulna tumors, and seven carpal bone tumors.

Patient data were obtained from hospital archives including, age, sex, the affected side, complaints at admission, tumor type, size and stage of the tumor. The Enneking surgical staging system was used for tumor staging (11). Tumor size was determined by the same musculoskeletal radiologist based on MRI and CT studies. All histopathological examinations were performed by the same pathologist. Surgical treatment methods and related complications were reviewed for benign and malignant tumors. Final Musculoskeletal Tumor Society System (MSTS) scores were used to assess functional outcomes.

The routine chemotherapy treatment protocol was IEVAC (ifosfamide, epirubicin, vincristine, adriamycin, cisplatin) for Ewing sarcoma patients. On the other hand, osteosarcoma patients received preoperative (neoadjuvant) and postoperative (adjuvant) chemotherapy, including epirubicin, cisplatin, ifosfamide at the same center.

All patients were called in for weekly follow-up visits for the first month after surgery and then every three months for the first year. Subsequently, patients with benign tumors were invited for follow-up visits every year, and malignant tumors, every six months. For the patients with malignant tumors, six-month follow-up visits included abdominal and thoracic computed tomography (CT) and positron emission tomography (PET) images.

Data were analyzed using SPSS v.21 (IBM Corporation, Armonk, NY, USA). The results were reported as descriptive statistics, namely mean, median, standard deviation, minimum and maximum, and percentage.

\section{RESULTS}

The study included 57 male and 36 female patients. The average follow-up period of the study was 32 months (range 16-163). There were 63 distal radius tumors, 23 distal ulna tumors, and seven carpal bone tumors. There were 82 benign and 11 malignant lesions. The lesions involved the right wrist in 65 patients and the left wrist in 28 patients (Table $\mathbf{1}$ ).

\begin{tabular}{|c|c|c|c|c|}
\hline 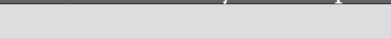 & Distal radius $n=63$ & Distal Ulna $n=23$ & Carpal bones $n=7$ & Total $\mathbf{n}=\mathbf{9 3}$ \\
\hline Male/female & $46 / 17$ & $7 / 16$ & $4 / 3$ & $57 / 36$ \\
\hline Benign/malign & $56 / 7$ & $19 / 4$ & $7 / 0$ & $82 / 11$ \\
\hline Right/left & $49 / 14$ & $14 / 9$ & $2 / 5$ & $65 / 28$ \\
\hline Age (year) $($ mean $\pm S D)$ & $22.9 \pm 14.01$ & $32.27 \pm 16.9$ & $39.2 \pm 11.9$ & $31.3 \pm 14.3$ \\
\hline Tumor size $(\mathrm{mm})($ mean $\pm \mathrm{SD})$ & $41 \pm 20.87$ & $29.8 \pm 19.9$ & $7 \pm 4$ & $25.9 \pm 14.9$ \\
\hline \multicolumn{5}{|l|}{ Tumor Stage } \\
\hline Stage 1 & 0 & 0 & 7 & 7 \\
\hline Stage 2 & 8 & 9 & 0 & 17 \\
\hline Stage 3 & 48 & 10 & 0 & 58 \\
\hline Stage IIA & 5 & 3 & 0 & 8 \\
\hline Stage IIB & 2 & 1 & 0 & 3 \\
\hline \multicolumn{5}{|l|}{ Complaint } \\
\hline Pain+swelling & 52 & 21 & 5 & 78 \\
\hline Deformity & 4 & 1 & 0 & 5 \\
\hline Incidental & 0 & 3 & 2 & 5 \\
\hline Pathological $\mathrm{fx}$ at diagnosis & 0 & 1 & 0 & 1 \\
\hline \multicolumn{5}{|l|}{ Tumor type } \\
\hline \multicolumn{5}{|l|}{ Benign } \\
\hline GCT & 26 & 10 & 0 & 36 \\
\hline $\mathrm{ABC}$ & 15 & 4 & 0 & 19 \\
\hline UBC & 4 & 0 & 0 & 4 \\
\hline Osteoblastoma & 3 & 0 & 0 & 3 \\
\hline Osteochondroma & 3 & 3 & 0 & 6 \\
\hline Enchondroma & 3 & 0 & 0 & 3 \\
\hline Osteoid osteoma & 1 & 1 & 0 & 2 \\
\hline Desmoid tumor & 1 & 0 & 0 & 1 \\
\hline IOGC & 0 & 1 & 7 & 8 \\
\hline \multicolumn{5}{|l|}{ Malign } \\
\hline Osteosarcoma & 2 & 1 & 0 & 3 \\
\hline Ewing sarcoma & 5 & 3 & 0 & 8 \\
\hline MSTS Last F-U mean (range) & $28(25-30)$ & $27(24-29)$ & $28(27-29)$ & $28(24-30)$ \\
\hline
\end{tabular}




\section{Distal Radius ( $\mathrm{n}=63$ )}

Distal radius was the most common site of involvement. The mean age of patients with distal radius tumors was $23 \pm 14$ years. Among these patients, 52 presented with pain and swelling in the wrist, and four had accompanying deformities. The mean tumor size was $41 \pm 20.87 \mathrm{~mm}$. Enneking stage 3 was the most common disease stage $(\mathrm{n}=48)$. The most common benign tumor in the distal radius was giant cell tumors (GCT, $n=26$ ), followed by aneurysmal bone cysts (ABC, $n=15$ ) (Figure 1). Benign distal radius tumors $(n=56)$ were treated with curettage and cementing $(n=45)$, curettage and grafting $(n=5)$, and marginal excision $(n=6)$ (Table 2). Malignant tumors of the distal radius $(n=7)$ included Ewing sarcoma $(n=5)$ and osteosarcoma $(n=2)$, all of which were treated with wide surgical resection and free vascularized fibular graft (FVFG) reconstruction (Figure 2). The postoperative splint was applied to all malignant radius tumors and 50 out of 56 benign tumors. Osteosynthesis with plate screw or percutaneous pinning was performed in all malignant patients and 32 benign patients. One patient developed a superficial infection and was treated with oral antibiotics. Three patients with GCTs in the distal radius developed local recurrence at an average of 76 months (range 54 to 93) after surgery (Table 3). These patients were treated with re-curettage and cementing. Four patients with Ewing sarcoma developed distant lung metastasis. They were treated with metastasectomy followed by chemotherapy. The mean final MSTS score of the patients with distal radius tumors was 28 (range 25-30).

\begin{tabular}{|lcccc|}
\hline \multicolumn{2}{|c|}{ Table 2. Surgical treatment types } & & & \\
\hline & $\begin{array}{c}\text { Distal } \\
\text { radius }\end{array}$ & $\begin{array}{c}\text { Distal } \\
\text { Ulna }\end{array}$ & $\begin{array}{c}\text { Carpal } \\
\text { bones }\end{array}$ & Total \\
\hline $\begin{array}{l}\text { Benign } \\
\text { Marginal resection }\end{array}$ & 6 & 5 & 1 & 12 \\
$\quad$ Curettage+graft & 5 & 7 & 6 & 18 \\
$\quad \begin{array}{l}\text { Curettage+PMMA } \\
\text { Malign }\end{array}$ & 45 & 7 & 0 & 52 \\
$\quad \begin{array}{l}\text { Wide resection+FVFG } \\
\quad \begin{array}{l}\text { Wide resection+strut } \\
\text { fibular graft }\end{array}\end{array}$ & 7 & 3 & 0 & 10 \\
\hline Abbreviations: PMMA: polymethyl methacrylate, FVFG: free vascularized fibular graft \\
\hline
\end{tabular}

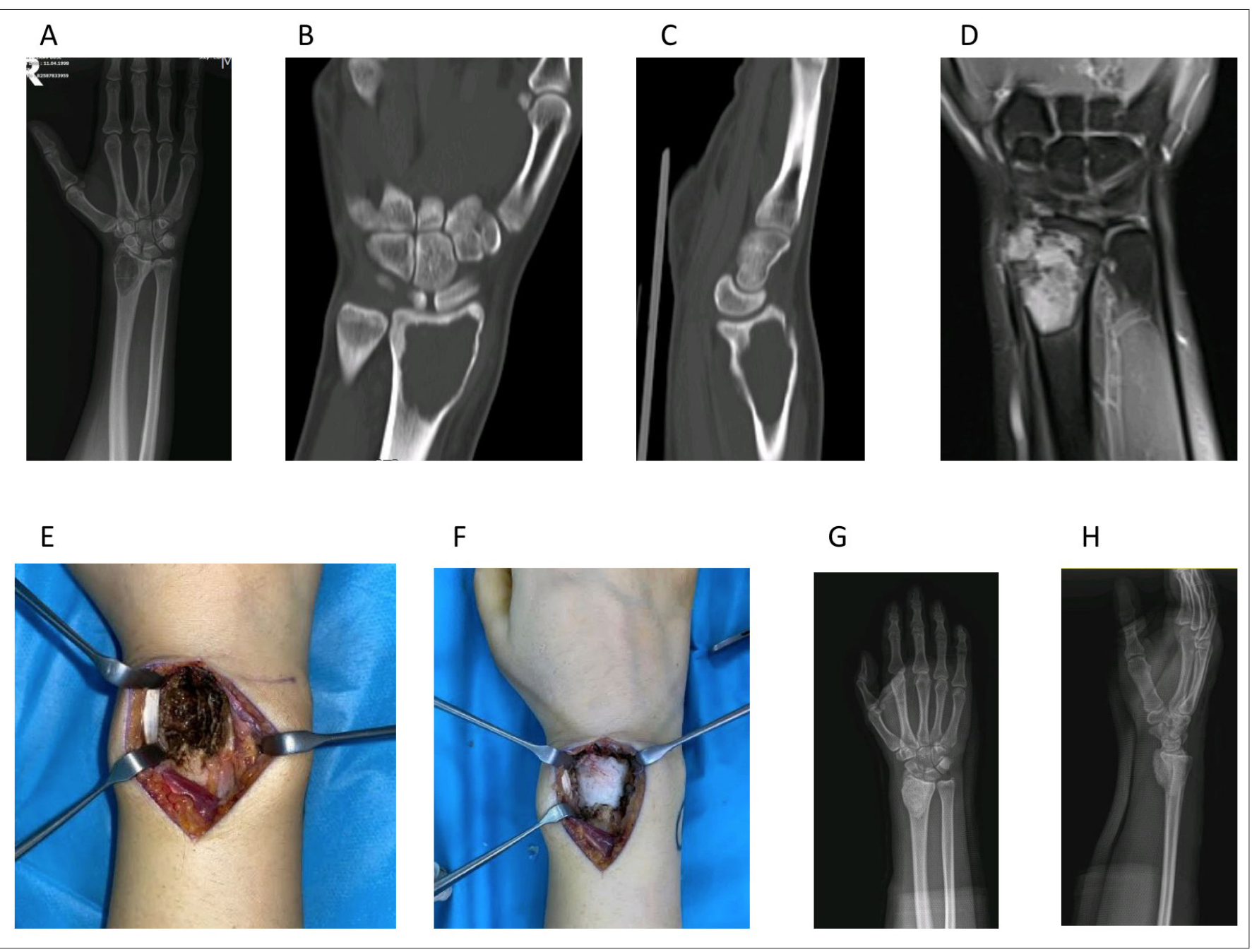

Figure 1. A 24-year-old female with distal radius giant cell tumor: a) preoperative plain radiograph, b,c) preoperative computarized tomography d) preoperative magnetic resonance image, e,f) the patient underwent curettage followed by cementation, g,h) postoperative plain radiograph. 


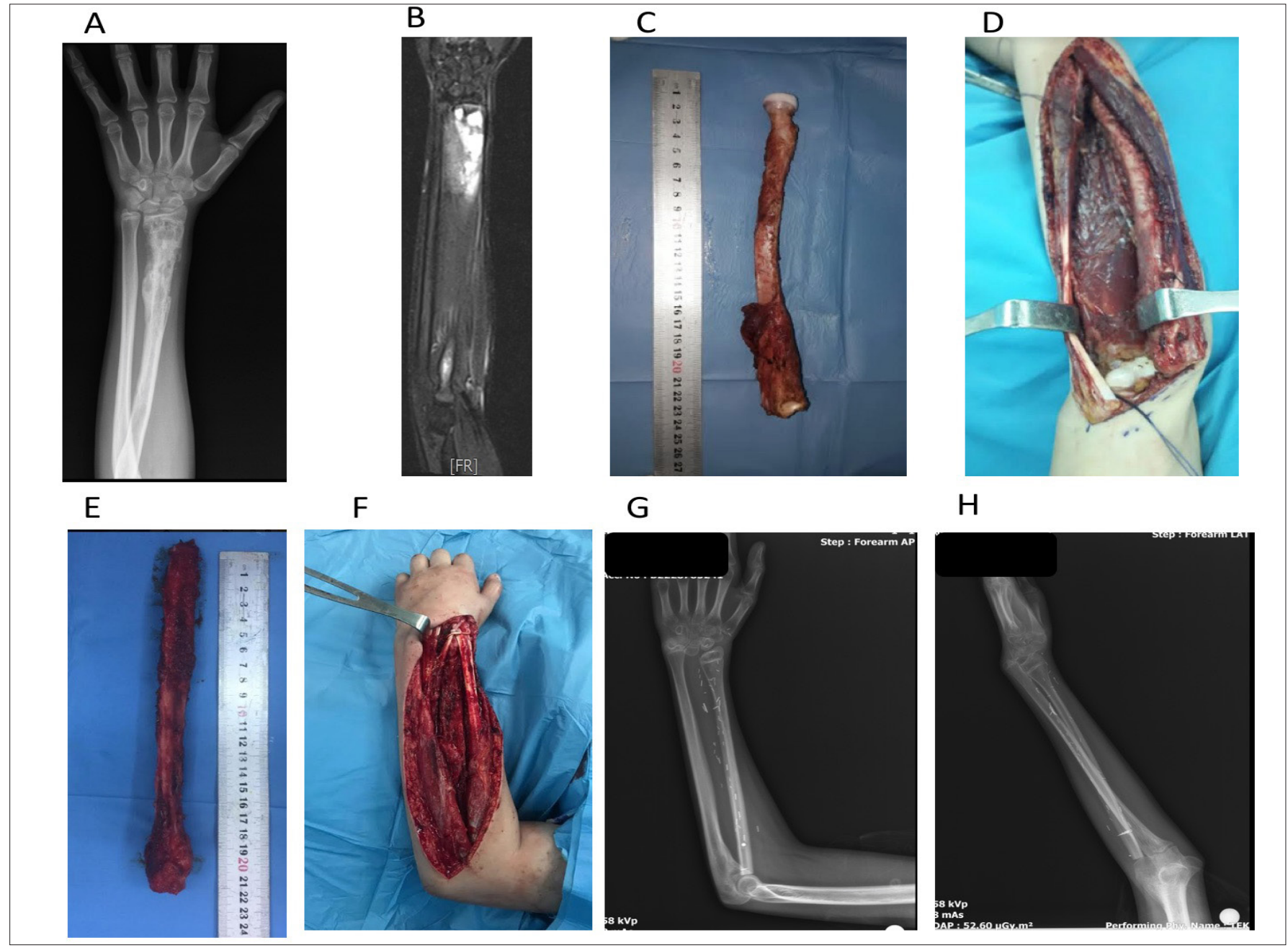

Figure 2. A 14-year-old female radius distal Ewing sarcoma, a) preoperative plain radiograph, b) preoperative magnetic resonance image, $\mathrm{c}, \mathrm{d}, \mathrm{e}, \mathrm{f})$ the patient had wide resection and biological reconstruction with osteoarticular vascularized fibular head graft, g,h) postoperative plain radiograph.

\begin{tabular}{|lcccc|}
\hline Table 3. Complication after surgical treatment & $\begin{array}{c}\text { Distal } \\
\text { radius }\end{array}$ & $\begin{array}{c}\text { Distal } \\
\text { Ulna }\end{array}$ & $\begin{array}{c}\text { Carpal } \\
\text { bones }\end{array}$ & Total \\
\hline Superficial infetion & 1 & 1 & 0 & 2 \\
Wound dehissance & 0 & 1 & 0 & 1 \\
Pathological fx. during F-U & 0 & 1 & 0 & 1 \\
Deformity during F-U & 0 & 1 & 0 & 1 \\
Local recurrence & 3 GCT & 1 GCT/1Ews & 0 & 5 \\
Distant metastasis & 4Ews & 1Ews & 0 & 5 \\
Abbreviations: F-U: follow-up, fx: fracture, GCT: giant cell tumor, Ews: Ewing sarcoma \\
\hline
\end{tabular}

\section{Distal Ulna $(\mathbf{n}=23)$}

The mean age of patients with distal ulna tumors was $32 \pm 17$ years. Twenty-one patients presented with pain and swelling, and one patient with wrist deformity. One patient had a pathological fracture at the time of admission. Three lesions were incidentally identified. The mean tumor size was $29.8 \pm 19.9 \mathrm{~mm}$. Enneking stage 3 was the most common disease stage. The most common benign tumor in the distal ulna was giant cell tumors (GCT, $\mathrm{n}=10$ ), followed by aneurysmal bone cysts $(A B C, n=4)$. Benign distal ulna tumors $(n=19)$ were treated with curettage and cementing $(n=7)$, curettage and grafting $(n=7)$, and marginal excision $(n=5)$ (Figure
3). Malignant tumors of the distal ulna $(n=4)$ included Ewing sarcoma $(n=3)$ and osteosarcoma $(n=1)$ and were treated with wide resection and FVFG $(n=3)$ and wide resection followed by strut fibular grafting $(n=1)$. The postoperative splint was applied to all malignant ulna tumors and 16 out of 19 benign tumors. Osteosynthesis with plate screw or percutaneous pinning was performed in all malignant patients and 12 benign patients. One patient developed a superficial infection and was treated with oral antibiotics. In follow-up, One patient with distal Ewing sarcoma developed a pathological fracture, and one patient developed a deformity. These patients were treated with reduction followed by osteosynthesis with plate and screws. Local recurrence was detected in one patient with a giant cell tumor and one patient with Ewing sarcoma. GCT recurrence was treated with recurettage and cementing. The recurrent Ewing sarcoma was treated with amputation. One patient with Ewing sarcoma developed lung metastasis at 42 months and underwent metastasectomy followed by chemotherapy. The mean final MSTS score of the patients with distal ulna tumors was 27 (range 24-30). 


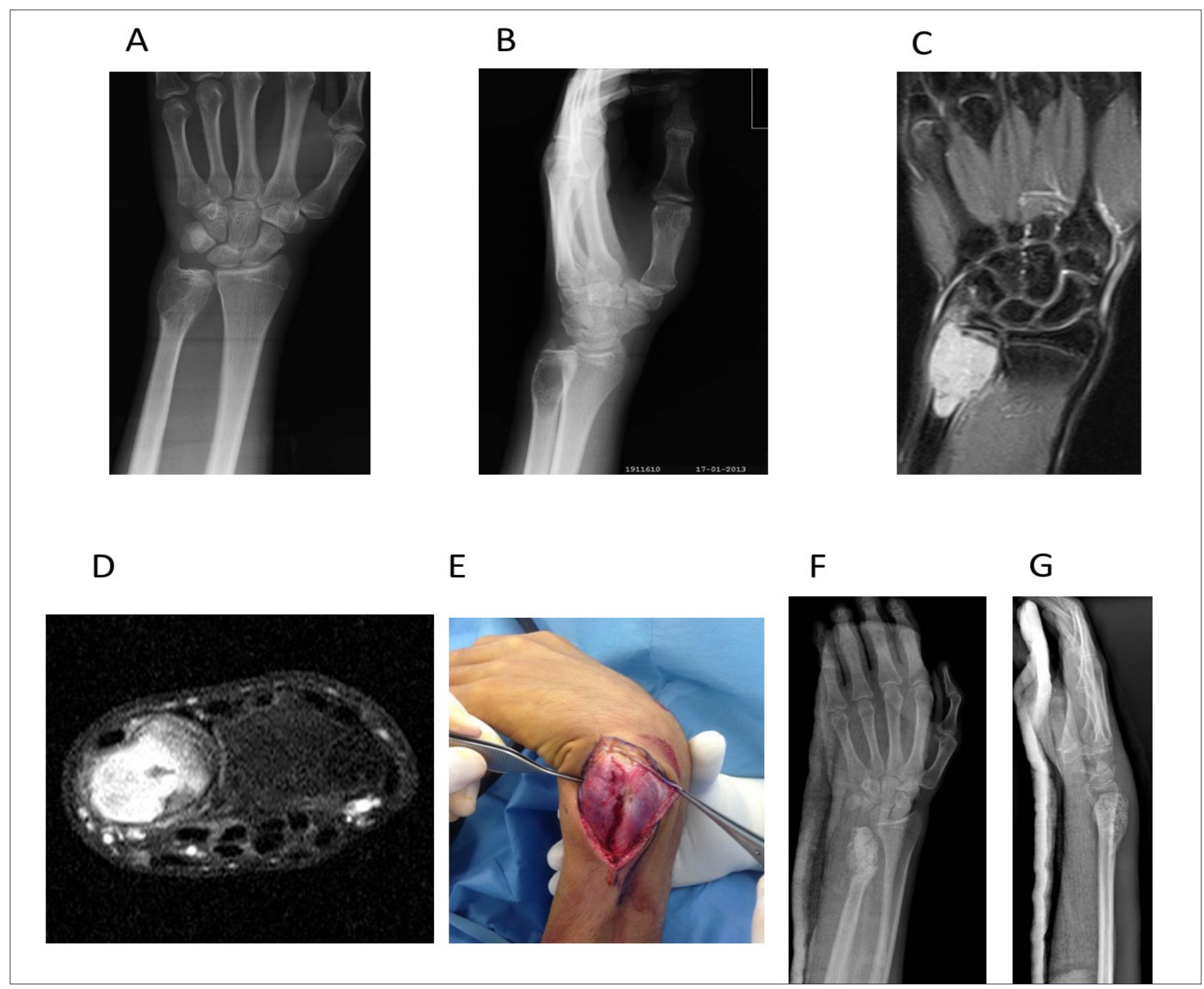

Figure 3. A 28-year-old male with distal ulna aneurysmal bone cyst a,b) preoperative plain radiograph, c,d) preoperative magnetic resonance image, e) the patient underwent curettage followed by grafting, f,g) postoperative plain radiograph.

\section{Carpal Bones $(\mathbf{n}=7)$}

Wrist tumors were the rarest in carpal bones $(n=7)$. The mean age in this subgroup was $39 \pm 12$ years. The mean tumor size was $7 \pm 4 \mathrm{~mm}$. Carpal bone lesions included scaphoid $(n=5)$ and lunate $(n=2)$ tumors. In all of these patients, pathological examination indicated intraosseous ganglion cysts. Five patients initially presented with pain and swelling, and two patients were incidentally identified. The patients were treated with curettage and grafting $(\mathrm{n}=6)$ and marginal excision $(\mathrm{n}=1)$. The mean final MSTS score of these patients was 28 (range 27-29). The postoperative splint was applied to all carpal benign tumors.

\section{DISCUSSION}

Bone tumors of the wrist are rare. Most benign tumors can be treated with curettage and cementing. The wide resection of malignant tumors remains a challenge for orthopedic oncologists due to the anatomical complexity of the hand and wrist region. This study reviewed the clinical, oncological, and functional outcomes of patients who were treated in a tertiary orthopedic oncology clinic for wrist bone tumors. In this study, the most common type of benign tumor was GCT, followed by ABC. The most common malignant tumor was Ewing sarcoma, and biological reconstruction yielded favorable outcomes in these patients. Locally recurrent GCTs were treated with re-operation, namely curettage and cement augmentation. One patient with Ewing sarcoma who developed local recurrence underwent secondary amputation. Two patients developed superficial infections and were treated with oral antibiotics.

The Rizzoli case archives indicate that wrist tumors accounted for only 400 (2.1\%) of the 18948 primary bone tumors (12). The literature presents case report series about the distal radius, distal ulna, and carpal bones (48). This study included 93 patients who were operated on for wrist tumors in a tertiary orthopedic oncology center over a 15-year period, indicating that the wrist region is a rare site for bone tumors. 
In our study, the most common tumor was GCT, and the lesions were most often localized in the distal radius. Different methods were described for the treatment of giant cell tumors. The most widely accepted treatment method is curettage, followed by cement augmentation (5). In our study, curettage with cement augmentation yielded favorable outcomes in patients with GCTs, in accordance with the literature. Crowe et al. (13) reported that $4(36 \%)$ out of $11 \mathrm{ABCs}$ of the distal upper extremity were localized in the wrist. In our study, ABCs comprised $20 \%$ of all wrist tumors. In our study, $\mathrm{ABC}$ sere mostly treated with curettage followed by grafting with success. None of these patients developed deformities or osteoarthritis in follow-up.

The literature reports that $84-100 \%$ of all distal radius tumors are Enneking stage $3(14,15)$. In our study, this number was $85.7 \%$, consistently with the literature. $71 \%$ of the malignant lesions were stage IIA at the time of admission. In our patient series, there were no patients with distant metastases (stage IIIB) at the time of diagnosis. We attribute this finding to rapid admission to the hospital after swelling or pain in the wrist.

When treating malignant tumors of the distal radius, we performed wide resection of the tumor, followed by autografting with a vascularized fibular head graft which is anatomically compatible with the distal radius. The literature reports outcomes for biological reconstruction with a fibular head graft (16). Previous studies have reported good functional outcomes for the hand due to the anatomical compatibility of the fibular head with the scapholunate joint $(16,17)$. In the current study, we obtained an average MSTS score of 26 (range 25-27) using vascularized fibular head grafts. Further larger studies with longer follow-up can more reliably demonstrate long-term outcomes.

Primary bone tumors of the ulna are quite rare (18). Rizzoli case archives indicate that only $0.9 \%$ of all primary bone tumors are localized in the ulna (12). In their series of 2000 patients, Exner et al. (19) reported ulnar involvement in 24 cases. Aycan et al. (18) showed that 8 of 23 primary tumors of the ulna were localized in the distal ulna. Consistently with the literature, we also observed that tumors in the distal ulna $(n=23)$ are rare. Although the primary reason of admission was pain and swelling for lesions in the distal ulna, one patient presented with a pathological fracture. In their series of primary tumors of the ulna, Aycan et al. (18) reported that the most common types of benign lesions were osteochondroma and $\mathrm{ABC}$, and the most common type of malignant lesion was osteosarcoma. In this study, the most common benign tumors involving the distal ulna were GCT and ABC, and the most common malignant lesion was Ewing sarcoma. Malignant tumors of the distal ulna were treated with wide resection and FVFG $(n=3)$, and strut fibular grafting $(n=1)$. The mean final MSTS score was 27 (range 24-29), indicating favorable functional outcomes. We believe that biological reconstruction is a promising method for the treatment of malignant tumors of the wrist.

There are several case series for primary tumors of carpal bones (6,7). Ozturk et al. (20) reported that 46 (4\%) of 1139 bone tumors were localized in the wrist. In our study, there were seven patients with carpal bone tumors ( 5 scaphoid, 2 lunate), all of which were identified as intraosseous ganglion cysts. Su et al. (21) stated that curettage and autologous bone grafting is an accepted treatment method for the treatment of intraosseous ganglion cysts of the carpal bone. In our study, six patients underwent curettage followed by autografting, and marginal excision was sufficient in 1 patient.

A giant cell tumor is a locally aggressive tumor and can locally recur. The literature reported a local recurrence rate of $3 \%$ to $28 \%$ for GCTs (22). In our study, 4 (11\%) out of 36 patients with GCT developed local recurrence. Several authors reported that using local adjuvants (alcohol phenol, hydrogen peroxide, iodine) after benign tumor curettage can reduce local recurrence (23). Chemical adjuvants were not used in any patient in our series. However, we believe that GCTs can recur locally or even metastasize to the lung, and therefore these patients should be closely followed up.

The limitations of our study are due to its retrospective design and small sample size. The functional outcome assessment may be biased. That said, functional assessment is included in each outpatient follow-up in our oncology clinic. Although different tumor types were presented without subtyping, our study is strong in that it demonstrates the incidence of primary tumors of a rare localization.

\section{CONCLUSION}

To conclude, primary bone tumors rarely involve the wrist compared to the other parts of the skeletal system. In our study, wrist tumors were most commonly localized in the distal radius. The most common type of benign tumor was GCT, and the most common type of malignant tumor was Ewing sarcoma. By treating GCTs with curettage and cementing and malignant tumors with wide resection and FVFG, we were able to obtain favorable clinical, oncological, and functional outcomes. Further larger studies with longer follow-ups are needed. 


\section{ETHICAL DECLARATIONS}

Ethics Committee Approval: The study was carried out with the permission of Marmara University Faculty of Medicine Clinical Research Ethics Committee (Date: 03.01.2020, Decision No: 09.2019.1033).

Informed Consent: Because the study was designed retrospectively, no written informed consent form was obtained from patients.

Referee Evaluation Process: Externally peer-reviewed.

Conflict of Interest Statement: The authors have no conflicts of interest to declare.

Financial Disclosure: The authors declared that this study has received no financial support.

Author Contributions: All of the authors declare that they have all participated in the design, execution, and analysis of the paper, and that they have approved the final version.

\section{REFERENCES}

1. Henderson M, Neumeister MW, Bueno Jr RA. Hand tumors: Benign and malignant bone tumors of the hand. Plast Reconstr Surg 2014; 133: 814-21

2. Payne WT, Merrell G. Benign bony and soft tissue tumors of the hand. J Hand Surg Am 2010; 35: 1901-10

3. Liu W, Wang B, Zhang S, Li Y, Hu B, Shao Z. Wrist reconstruction after en bloc resection of bone tumors of the distal radius. Orthop Surg, 2021; 13: 376-83.

4. Yang YF, Wang JW, Huang $\mathrm{P}, \mathrm{Xu} \mathrm{ZH}$. Distal radius reconstruction with vascularized proximal fibular autograft after en-bloc resection of recurrent giant cell tumor. BMC Musculoskelet Disord 2016; 17: 1-6.

5. Mozaffarian K, Modjallal M, Vosoughi AR. Treatment of giant cell tumor of distal radius with limited soft tissue invasion: curettage and cementing versus wide excision. J Orthop Sci 2018; 23: 174-9.

6. Xarchas K, Leviet CD. Osteoblastoma of the carpal scaphoid: frequency and treatment. Acta Orthop Belg, 2002; 68: 532-6.

7. Murray PM, Berger RA, Inwards CY. Primary neoplasms of the carpal bones. J Hand Surg 1999; 24: 1008-13.

8. Zou C, Lin T, Wang B, et al. Managements of giant cell tumor within the distal radius: a retrospective study of 58 cases from a single center. J Bone Oncol 2019; 14: 100211.

9. Pradhan A, Reddy KIA, Grimer RJ, et al. Osteosarcomas in the upper distal extremities: Are their oncological outcomes similar to other sites?. Eur J Surg Oncol 2015; 41: 407-12.

10.Erol B, Sofulu O. Tricks and pitfalls in the surgical treatment of malignant bone tumours of the forearm in children and adolescents. J Child Orthop 2021; 15: 366-71.

11.Enneking WF, Spanier SS, Goodman MA. The classic: a system for the surgical staging of musculoskeletal sarcoma. Clin Orthop Relat Res 2003; 415: 4-18.

12.Picci P, Manfrini M, Fabbri N, Gambarotti M, Vanel. Atlas of musculoskeletal tumors and tumorlike lesions: the Rizzoli case archive. Springer Science \& Business Media 2014; 5-9.

13. Crowe MM, Houdek MT, Moran SL, Kakar S Aneurysmal bone cysts of the hand, wrist, and forearm J Hand Surg 2015; 40: 2052 7.

14.Qi DW, Wang P, Ye ZM, et al. Clinical and radiographic results of reconstruction with fibular autograft for distal radius giant cell tumor. Orthop Surg 2016; 8: 196-204.
15. Salunke AA, Chen Y, Chen X, et al. Does pathological fracture affect the rate of local recurrence in patients with a giant cell tumour of bone? A meta-analysis. Bone Joint J 2015; 97: 1566-71.

16. Chung DW, Han CS, LeeJH, Lee SG. Outcomes of wrist arthroplasty using a free vascularized fibular head graft for Enneking stage II giant cell tumors of the distal radius. Microsurgery, 2013; 33: 1128.

17. Jaminet P, Rahmanian-Schwarz A, Pfau M, Nusche A, Schaller HE, Lotter O. Fibulo-scapho-lunate arthrodesis after resection of the distal radius for giant-cell tumor of the bone. Microsurgery 2012; 32; 458-62.

18. Aycan OE, Sökücü S, Özer D, Çetinkaya E, Arıkan Y, Kabukçuoğlu YS. Primary bone tumors and tumor like lesions of the ulna. Acta Orthop Traumatol Turc 2019; 53: 30-4.

19. Exner GU, von Hochstetter AR, Honegger $H$, Schreiber A. Osseous lesions of the distal ulna: atypical location-unusual diagnosis. Arch Orthop Trauma Surg 2000; 120: 219-23.

20. Öztürk R, Arıkan ŞM, Bulut EK, Kekeç AF, Çelebi F, Güngör $\mathrm{BSS}$. Distribution and evaluation of bone and soft tissue tumors operated in a tertiary care center. Acta Orthop Traumatol Turc 2019; 53: 189-94.

21.Li S, Sun C, Zhou X, Shi J, Han T, Yan H. Treatment of intraosseous ganglion cyst of the lunate: a systematic review. ann plast surg 2019; 82: 577-81.

22.Kang L, Manoso MW, Boland PJ, Features of grade 3 giant cell tumors of the distal radius associated with successful intralesional treatment J Hand Surg 2010; 35: 1850-7

23. Bickels J, Campanacci DA. Local adjuvant substances following curettage of bone tumors. JBJS 2020; 102: 164-74. 